\title{
ARTIGO CIENTÍFICO \\ Adubação verde de feijoeiro em consórcio com cafeeiro na agricultura familiar de Araponga, Minas Gerais
}

\section{Green manuring of beans intercropped with coffee in family farming of Araponga, Minas Gerais, Brazil}

\author{
Filipe Fernandes de Sousa ${ }^{1 *}$, Ricardo Henrique Silva Santos ${ }^{2}$, José Eustáquio de Souza Carneiro $^{3}$, Segundo Urquiaga ${ }^{4}$
}

Resumo: O cultivo do feijão consorciado é prática comum entre agricultores da Zona da Mata Mineira, os quais promovem a diversificação produtiva de suas áreas visando principalmente a produção de alimentos para consumo da família. Diagnósticos de projetos de extensão universitária identificaram agricultores familiares que, além do consorcio com café, utilizam leguminosas em pré-cultivo ao feijão para fins de adubação verde, incrementando os processos biológicos que contribuem para a complexidade e sustentabilidade dos agroecossistemas. Assim, objetivou-se avaliar espécies de leguminosas em pré-cultivo e sua influência sobre o feijoeiro em sistema de consórcio com cafeeiro, sob manejo da agricultura familiar. A avaliação foi conduzida em uma propriedade rural e conjuntamente com o agricultor familiar. As leguminosas avaliadas foram o feijão-deporco e a lablabe, além de uma testemunha, representada pela vegetação espontânea. Foi adotado o delineamento de blocos casualizados, com oito repetições, onde cada entrelinha de cafeeiros representou um bloco. As variáveis analisadas foram produtividade de matérias fresca e seca; teor e acúmulo de N; contribuição da FBN nos pré-cultivos e produtividade do feijão cultivado em sucessão. O feijão-de-porco foi a leguminosa que apresentou a maior produção de matérias fresca e seca (19,04 e $4,25 \mathrm{t} \mathrm{ha}^{-1}$, respectivamente), acumulou mais $\mathrm{N}\left(113,99 \mathrm{~kg} \mathrm{ha}^{-1}\right)$ e aportou a maior quantidade de $\mathrm{N}-\mathrm{FBN}$ ao sistema $(49,18 \mathrm{~kg}$ $\mathrm{ha}^{-1}$ ). No entanto, o pré-cultivo com leguminosas não influenciou a produtividade do feijoeiro cultivado em sucessão.

Palavras-chave: Fixação biológica de nitrogênio; Lablabe; Feijão-de-porco; Pesquisa participativa.

\begin{abstract}
Bean intercropping cultivation is common practice among farmers in the Zona da Mata, Minas Gerais, which promote the diversification production of their areas aiming mainly the production of food for family consumption. Diagnostics of university extension projects identified family farmers who beside the consortium with coffee trees, use legumes in pre-cultivation to beans for green manure, increasing biological process that contribute to the complexity an sustainability agroecosystems. Thus, the objective of this work was to evaluate species of leguminous plants in pre cultivation and the influence on the bean in consortium system with coffee under the management in the family farmer. The evaluation was conducted in rural property and jointly with the farmer. The evaluated legumes were the jack bean and the hyacinth bean, besides a witness represented by the spontaneous vegetation. A randomized block design with eight replications was adopted, with each interlayer of coffee trees representing one block. The variables analyzed were: fresh and dry matter productivity; content and accumulation of N; contribution of BNF in preculture; and productivity of beans grown in succession. The jack bean was the legumes that presented the largest production of fresh and dry matter (19.04 and $4.25 \mathrm{t}$ ha-1, respectively), accumulated more N (113.99 kg ha-1) and contributed the largest amount of N-system FBN (49.18 kg ha-1). However, precultivation with legumes did not influence the productivity of the bean grown in succession.
\end{abstract}

Key words: Biological fixation of nitrogen; Lablabe; Jack bean; Participatory research.

\footnotetext{
*Autor para correspondência

Recebido para publicação em 14/06/2017; aprovado em 11/09/2017

${ }^{1}$ Mestre, Universidade Federal de Viçosa, Viçosa, Minas Gerais. Fone: (31) 992812291. E-mail:filipe_fernandes08@yahoo.com.br.

${ }^{2}$ Professor Doutor, Universidade Federal de Viçosa. E-mail: rsantos@ufv.br

${ }^{3}$ Professor Doutor, Universidade Federal de Viçosa. E-mail: jesc@ufv.br

${ }^{4}$ Pesquisador Doutor, Empresa Brasileira de Pesquisa Agropecuária - Embrapa Agrobiologia, E-mail: segundo.urquiaga@embrapa.br
} 


\section{INTRODUÇÃO}

O consórcio do feijoeiro (Phaseolus vulgaris L.) é uma prática comum no Brasil. Em Minas Gerais, tradicionalmente, essa cultura é cultivada em consórcio. Estima-se que de 50 a $70 \%$ do feijão produzido seja proveniente de cultivos consorciados, chegando a atingir, em certas áreas, de 90 a $100 \%$ da produção (VIEIRA, 2006). Todavia, na agricultura familiar, onde predominam os cultivos consorciados, a produtividade média do feijoeiro é considerada baixa, variando entre 650 e $850 \mathrm{~kg} \mathrm{ha}^{-1}$ (DIDONET et al., 2009).

$\mathrm{Na}$ realidade da Zona da Mata Mineira, os agricultores familiares encontram-se em região de relevo ondulado, com poucas áreas planas e em pequenas propriedades. Por estes motivos o feijão geralmente é cultivado entre os cafezais, espaço disponível para o cultivo, visando a maximização do uso da área. Outro fator relevante, é que a produção dessa cultura está intimamente relacionada com a subsistência, onde nem sempre aumentar a produtividade é mais importante do que produzir para o sustento da família (DIDONET et al., 2009).

Com efeito, o feijoeiro apresenta características que favorecem o seu cultivo consorciado e consequentemente a ampliação do uso dessa prática por agricultores familiares. Apresenta ciclo curto, é pouco competitivo, relativamente tolerante à competição movida pela cultura consorciada e alcança preços atraentes no mercado (VIEIRA, 2006).

Destarte, a adoção de práticas agrícolas que maximizem os processos biológicos e que sejam compatíveis com as condições da agricultura familiar, são fundamentais para o aumento da produtividade do feijoeiro neste segmento. Neste contexto, o pré-cultivo de leguminosas é uma estratégia com elevado potencial.

Relatos dos agricultores da Zona da Mata Mineira e das referências de literaturas recentes (MOITINHO et al., 2011; FERREIRA et al., 2011; LAZARO et al., 2013) comprovam que essa prática pode ser eficiente, se utilizada sob condições adequadas.

Com o uso de leguminosas, é possível promover a contínua cobertura do solo (CARVALHO et al., 2013), aportar quantidades significativas de matéria orgânica para o sistema (CUNHA et al., 2011; CORREIA et al., 2008) e reciclar nutrientes.

A principal vantagem da utilização de leguminosas em pré-cultivos é a possibilidade de incorporar nitrogênio $(\mathrm{N})$ por via de Fixação Biológica (FBN) ao agroecossistema (AMBROSANO et al., 2013; PIETSCH et al., 2007; VIOLA et al., 2013).

Com o aporte de N-FBN dos pré-cultivos, é possível beneficiar a cultura em sucessão, elevando a produtividade e contribuindo para a redução do uso de fertilizantes nitrogenados sintéticos. No entanto, existem relatos da contribuição significativa do fornecimento de $\mathrm{N}$ sem reflexo no aumento da produtividade (CASTRO et al., 2004).

No Estado do Mato Grosso do Sul, o feijão comum, quando cultivado em sucessão ao feijão-de-porco e à crotalária, apresenta elevado rendimento de grãos (GALLO et al., 2015). Resultados semelhantes foram encontrados no município de Viçosa, MG, em que o pré-cultivo com o feijãode-porco aportou quantidade considerável de $\mathrm{N}$ por via da FBN ao agroecossitema, e elevou a produtividade do feijoeiro cultivado em sucessão (SOUSA et al., 2016).
Pesquisa participativa para avaliar a produtividade do feijoeiro cultivado em sucessão aos adubos verdes, no Estado do Mato Grosso, relata que o feijão em cultivo solteiro, quando semeado sobre a palhada das leguminosas apresenta rendimento de grãos maior do que quando semeado sobre palhada de gramíneas (PADOVAN et al., 2012). Os autores reforçam que as avaliações conduzidas conjuntamente com agricultores locais foram eficientes na mensuração dos atributos de desempenho do feijoeiro.

O envolvimento de outros atores na pesquisa participativa é estratégia importante, pois permite aos agricultores identificarem as potencialidades e as desvantagens da adoção das práticas e das espécies que serão avaliadas (SILVA et al., 2014). Além disso, preenche a lacuna que existe entre os produtores de informação e aqueles que de fato a utilizarão (SILVA; ARAÚJO NETO, 2011).

Diante desse contexto, presume-se que para a adubação verde se consolidar como prática comum na agricultura familiar, pesquisas também devem ser realizadas em propriedades rurais e com a efetiva participação do agricultor. Ressalta-se que as leguminosas apresentam características peculiares, principalmente em relação à quantidade de massa produzida, ao teor e ao acúmulo de $\mathrm{N}$ fixado biologicamente $\mathrm{e}$ à taxa de decomposição, que sofrem grande influência das interações edafoclimáticas locais e também do manejo adotado pelo agricultor.

Com efeito, outros fatores podem se tornar limitantes na adoção da prática, como os custos, o retorno econômico, a finalidade do cultivo, a produtividade pretendida $\mathrm{e}$, consequentemente a adubação a ser empregada, além do espaço disponível no cafezal.

Por essas razões, objetivou-se com este trabalho, avaliar o pré-cultivo de leguminosas ao feijoeiro consorciados com cafeeiros, sob as condições da agricultura familiar da Zona da Mata de Minas Gerais.

\section{MATERIAL E MÉTODOS}

\section{Localização e características da área experimental}

$\mathrm{O}$ experimento foi conduzido com agricultor familiar da comunidade rural Salazar, do município de Araponga, Zona da Mata Mineira, situado a $20^{\circ} 42^{\prime}$ S e $42^{\circ} 32^{\prime} \mathrm{O}$, a $1200 \mathrm{~m}$ de altitude. Os cafeeiros são manejados na área há mais de 25 anos, com poucos tratos culturais e apresentam copas densas, de aproximadamente 1,0 $\mathrm{m}$ de diâmetro. Culturas como feijão e milho são cultivadas em consórcio.

O clima da região, segundo a classificação de Köppen, é do tipo $\mathrm{Cwb}$, com temperatura média anual de $18{ }^{\circ} \mathrm{C}$ e precipitação média anual de $1.300 \mathrm{~mm}$.

O solo da área é Latossolo Vermelho-Amarelo, Aproeminente, do qual foram coletadas amostras, na profundidade de $0-20 \mathrm{~cm}$, nas entrelinhas dos cafeeiros. Os resultados da análise química de rotina e matéria orgânica foram: $\mathrm{pH}$ em $\mathrm{H}_{2} \mathrm{O}=6,3 ; \mathrm{P}=3,3 \mathrm{mg} / \mathrm{dm}^{3} ; \mathrm{K}=104 \mathrm{mg} / \mathrm{dm}^{3}$; $\mathrm{Ca}=3,8 / \mathrm{cmol}_{\mathrm{c}} / \mathrm{dm}^{3} ; \mathrm{Mg}=1.26 \mathrm{cmol}_{\mathrm{c}} / \mathrm{dm}^{3} ; \mathrm{H}+\mathrm{AL}=6,6$ $\mathrm{cmol}_{\mathrm{c}} / \mathrm{dm}^{3} ; \mathrm{V} \%=41,1 ; \mathrm{MO}=4,54 \mathrm{dag} / \mathrm{kg} ; \mathrm{P}-\mathrm{rem}=17,47$ $\mathrm{mg} / \mathrm{L}$.

\section{Tratamentos e delineamento experimental}

Foi adotado o delineamento em blocos casualizados, com oito repetições. Os tratamentos consistiram em três précultivos: lablabe (Dolichos lablab), feijão-de-porco (Canavalia ensiformis) e a testemunha, representada pela 
vegetação espontânea. Cada entrelinha dos cafeeiros, com espaçamento de 3,5 x 1,7 m, representou um bloco. A parcela experimental foi constituída por três linhas de $7 \mathrm{~m}$ espaçadas em $60 \mathrm{~cm}$, onde foram cultivados os pré-cultivos e o feijoeiro. Entretanto, a área total da parcela foi estimada em $24,5 \mathrm{~m}^{2}$ por também considerar a área ocupada pelos cafeeiros.

\section{Plantio e tratos culturais}

Antes da instalação do experimento, o preparo do solo foi realizado com enxada rotativa e microtrator. Os précultivos foram semeados no dia 19/11/2012, sem adubação, na densidade de nove sementes por metro, para o feijão-deporco, e três sementes por cova, para a lablabe, as quais eram espaçadas de $30 \times 60 \mathrm{~cm}$. Foi realizada uma capina 17 dias após a semeadura.

O corte da parte aérea dos pré-cultivos ocorreu três meses e 17 dias após a semeadura, quando apenas o feijão-deporco encontrava-se em pleno florescimento. O agricultor considera o crescimento da lablabe agressivo aos cafeeiros, devido ao hábito trepador, por isso não considerou interessante a espera da sua floração. Após o corte, os materiais vegetais foram mantidos na superfície do solo por sete meses e, posteriormente, incorporados com enxada rotativa, antes do cultivo do feijão. Ressalta-se que este tipo de manejo, inclusive o período de manutenção da palhada sobre o solo é o mesmo adotado pelo agricultor em seu sistema produtivo.

A semeadura do feijoeiro, conhecido pelo agricultor como 'Moura rosa' (Phaseolus vulgaris), de hábito de crescimento indeterminado, ocorreu 24 dias após o revolvimento do solo. Foi utilizada plantadeira manual, regulada para três sementes por cova. $\mathrm{Na}$ ocasião da semeadura foi feita adubação, com aplicação de $6,5 \mathrm{~g} \mathrm{cova}^{-1}$ do formulado 4-14-8, que equivaleria a $498 \mathrm{~kg} \mathrm{ha}^{-1}$ desse formulado, caso fosse feito o cultivo solteiro.

\section{Coleta de material e avaliações}

No corte dos pré-cultivos, foram amostradas as partes aéreas das plantas em uma área de $1,8 \mathrm{~m}^{2}$ por parcela. Foi medido $1,0 \mathrm{~m}$ em cada lateral e coletado todo o material contido dentro do retângulo formado, determinando-se a massa da matéria fresca. Posteriormente, foi coletada uma subamostra, que foi pesada, acondicionada em estufa com circulação forçada de ar, a $65^{\circ} \mathrm{C}$, até atingir massa constante, e pesada novamente, para determinação da massa da matéria seca. Após a secagem, o material foi moído em moinho tipo Willey, e as amostras levadas ao laboratório para determinação do teor de $\mathrm{N}$ total, pelo método de Kjeldhal (BREMMER; MULVANEY, 1982).

A contribuição da FBN para o feijão-de-porco e para a lablabe foi estimada pela técnica de abundância natural de ${ }^{15} \mathrm{~N}$ (delta, $\delta^{15} \mathrm{~N}$ ) (BODDEY et al., 1994), em espectrômetro de massa Finnigan MAT, modelo Delta Plus, no Laboratório John M. Day de Isótopos estáveis, da Embrapa Agrobiologia. A contribuição da FBN foi estimada pela equação 1 .

NFBN $=100 \times \frac{\delta 15 \mathrm{~N} \text { Testemunha- } \delta 15 \mathrm{~N} \text { Leguminosas }}{\delta 15 \mathrm{~N} \text { Testemunha- } \beta}$

Em que: $\delta{ }^{15} \mathrm{~N}$ testemunha; o valor de $\delta{ }^{15} \mathrm{~N}$, obtido da planta não fixadora (testemunha); $\beta$ : $-1,1$ (valor da discriminação isotópica quando $\delta{ }^{15} \mathrm{~N}=0 \%$ ).
A testemunha foi representada pelas ervas espontâneas mais abundantes na área, que foram a voadeira (Conyza bonariensis), picão (Bidens pilosa) e sapé (Imperata brasiliensis).

A estimativa da produção de grãos do feijoeiro foi feita pela colheita de cada parcela, desprezando-se $0,5 \mathrm{~m}$ das extremidades. Após ser realizada a secagem, até teor de umidade de $13 \%$, os grãos foram pesados e os valores convertidos para $\mathrm{kg} \mathrm{ha}^{-1}$.

Por se tratar de um sistema consorciado, após extrapolar a produção para $\mathrm{t} \mathrm{ha}^{-1}$, tanto da massa produzida pelos précultivos, quanto da produtividade do feijoeiro, foi feita a correção para valores que condizem com a realidade da área plantada, com base na equação 2 .

$$
\begin{gathered}
3,50 \mathrm{~m}-1,70 \mathrm{~m} \text { (área com café) }=1,80 \mathrm{~m} \\
X=\frac{1,80 \times 100}{3,50}=51 \%
\end{gathered}
$$

Assim: Produtividade real $\left(\mathrm{t} \mathrm{ha}^{-1}\right)=$ Produtividade obtida $\mathrm{x}$ 0,51

\section{Análises estatísticas}

Para avaliação da influência dos tratamentos sobre as variáveis analisadas, foi utilizado o software estatístico Sisvar 5.3 (FERREIRA, 2011). Os dados foram submetidos à análise de variância, pelo teste $\mathrm{F}$, e as médias foram comparadas pelo teste de Tukey $(\mathrm{p}<0,05)$.

\section{RESULTADOS E DISCUSSÃO}

Entre os pré-cultivos avaliados, o feijão-de-porco produziu mais matéria fresca e seca que a lablabe e a testemunha, os quais também apresentaram diferenças significativas entre si (Tabela 1). Esse resultado pode ser atribuído à época de corte dos pré-cultivos, que favoreceu o feijão-de-porco. No período avaliado, apenas essa espécie se encontrava em pleno florescimento, por causa de seu ciclo curto e seu rápido crescimento inicial (FAVERO et al., 2001). A lablabe, por apresentar características diferentes, mostrou menor produção de massa, mas superior à da testemunha.

A produção de matéria fresca e seca do feijão-de-porco, comparada com os valores citados na literatura (CAVALCANTE et al., 2012; CARVALHO et al., 2013), pode ser considerada alta, por se tratar de um sistema consorciado, com baixa população de plantas, e pela possível competição exercida pelos cafeeiros. Entretanto, os valores encontrados para a lablabe foram baixos, embora nutrientes sejam absorvidos e quantidades maiores de massa produzidas até o estádio de florescimento (OLIVEIRA et al., 2013). Ressalte-se que os resultados encontrados na literatura são para as espécies em cultivo solteiro, onde a produção de $6 \mathrm{t}$ $\mathrm{ha}^{-1}$ de resíduo é considerada adequada para uma boa cobertura do solo (ALVARENGA et al., 2001)

Nas condições do município de Viçosa, MG, foram encontrados, para a lablabe, aos 107 dias, uma produção de 5 $\mathrm{t} \mathrm{ha}^{-1}$ e, para o feijão-de-porco, de $8 \mathrm{t} \mathrm{ha}^{-1}$ de matéria seca, ambos em consórcio com cafeeiros (CARDOSO, 2013). Nesta pesquisa, o maior espaçamento dos cafeeiros contribuiu para a obtenção de valores maiores de produção de massa, favorecida pela maior incidência de luz nas entrelinhas e, consequentemente, melhores condições de crescimento para a planta. 
Tabela 1. Produção de matéria fresca, matéria seca. Teor e acúmulo de $\mathrm{N}$ na parte aérea de lablabe e do feijão-de-porco e a contribuição da N-FBN nessas espécies. Araponga, Minas Gerais

\begin{tabular}{|c|c|c|c|c|c|c|}
\hline \multirow{2}{*}{ Tratamento } & Matéria Fresca & Matéria Seca & \multirow{2}{*}{$\begin{array}{c}\text { Teor de } \mathrm{N} \\
\%\end{array}$} & \multirow{2}{*}{$\begin{array}{l}\text { Acúmulo de N } \\
\mathrm{kg} \mathrm{ha}^{-1}\end{array}$} & \multirow{2}{*}{$\begin{array}{c}\text { N-FBN } \\
\%\end{array}$} & \multirow{2}{*}{$\begin{array}{l}\text { N-FBN } \\
\mathrm{kg} \mathrm{ha}^{-1}\end{array}$} \\
\hline & \multicolumn{2}{|c|}{$\mathrm{t} \mathrm{ha}^{-1}$} & & & & \\
\hline Lablabe & $12,13 \mathrm{~b}$ & $2,75 \mathrm{~b}$ & $1,75 \mathrm{~b}$ & $48,12 \mathrm{~b}$ & 31,14 & 14,91 \\
\hline Feijão-de-porco & $19,42 \mathrm{a}$ & $4,33 \mathrm{a}$ & $2,68 \mathrm{a}$ & $116,04 \mathrm{a}$ & 43,15 & 50,07 \\
\hline Testemunha & $8,51 \mathrm{c}$ & $1,70 \mathrm{c}$ & $1,99 \mathrm{~b}$ & $33,83 \mathrm{c}$ & ---- & ---- \\
\hline $\mathrm{CV}(\%)$ & 16,73 & 16,15 & 9,85 & 13,97 & --- & ---- \\
\hline
\end{tabular}

Médias seguidas pela mesma letra, na coluna, não diferem entre si pelo teste de Tukey a $5 \%$ de probabilidade. Valores de massa e acúmulo de $\mathrm{N}$ e $\mathrm{N}-$ FBN já corrigidos para área real ocupada pelos adubos verdes.

Esses fatores também contribuíram para a produção de matéria seca das leguminosas em consórcio com cafeeiros nas condições do município de Rio Pomba, MG. Aos 120 dias de consórcio, foram produzidas 2,65 e 2,89 $\mathrm{t} \mathrm{ha}^{-1}$ de feijão-deporco, no primeiro e no segundo ano, respectivamente. Entretanto, para a lablabe, sob as mesmas condições de cultivo, foi relatado a produção de 1,89 e 5,74 $\mathrm{t} \mathrm{ha}^{-1}$ no primeiro e no segundo ano, respectivamente, resultado esse do segundo ano, superior ao encontrado nesta pesquisa (BARRELLA, 2010).

A diferença de produção de matéria fresca entre as espécies foi identificada, in loco, também pelo agricultor, embora não tenha sido parte do experimento, mensurar a cobertura do solo. Ele ressalta que, na situação avaliada, o rápido desenvolvimento do feijão-de-porco possibilitou maior cobertura do solo, proporcionando também a redução da incidência de algumas ervas espontâneas, identificadas em outras áreas.

$\mathrm{O}$ feijão-de-porco apresentou maior teor de $\mathrm{N}$ em sua massa (Tabela 1). O estádio vegetativo no período avaliado pode ter contribuído para esse maior teor, pois na floração os teores do nutriente são os mais elevados (CARVALHO et al., 2013).

$\mathrm{O}$ acúmulo de $\mathrm{N}$ na parte aérea do feijão-de-porco foi 2,4 vezes maior em relação à lablabe e 3,4 vezes em relação à testemunha. A maior produção de massa e maior concentração de $\mathrm{N}$ contribuíram para obtenção desses valores. $\mathrm{O}$ acúmulo de $\mathrm{N}$ pela lablabe foi superior ao da testemunha, comprovando a eficiência da leguminosa em aporte de $\mathrm{N}$ ao agroecossistema, mesmo sob baixas produções de massa.

As concentrações de N-FBN variaram entre as espécies (Tabela 1). Mais de $40 \%$ do $\mathrm{N}$ absorvido pelo feijão-de-porco foi proveniente da fixação biológica. Para a lablabe, pouco mais de $30 \%$ do $\mathrm{N}$ foi proveniente dessa simbiose. A contribuição da FBN, encontrada neste estudo para o feijãode-porco, foi menor do que os $81 \%$ relatados para a consorciação com cafeeiros nas condições do Estado do Espírito Santo (PARTELLI et al. 2011).

A maior concentração de N-FBN, aliada à alta produção de massa seca, resultou em maior acúmulo de N-FBN no feijão-de-porco (Tabela 1). Aproximadamente $50 \mathrm{~kg} \mathrm{ha}^{-1}$ de $\mathrm{N}$ foram incorporados ao sistema, provenientes da FBN, 3,3 vezes mais do que o acumulado pela lablabe.

A quantidade de N-FBN acumulada pelo feijão-de-porco está coerente com a relatada na literatura, por se tratar de plantio consorciado (PARTELLI et al., 2011), embora valores maiores sejam relatados na literatura para o cultivo solteiro (AMBROSANO et al., 2013; VARGAS et al., 2011). A ausência de inoculação das sementes pode ter contribuído para o comprometimento do estabelecimento e para a eficiência da simbiose entre as bactérias fixadoras de $\mathrm{N}$ e as leguminosas (PARTELLI et al., 2011). Além disso, o baixo teor de $\mathrm{P}$ no solo pode ter sido fator importante, tendo em vista que esse nutriente auxilia na nodulação, pela transferência de energia, e no aumento do número de pelos radiculares, proporcionando mais sítios de infecção para a bactéria (OTHMAN et al., 1991; OKELEYE e OKELANA, 1997).

Com base no histórico de manejo da área, é possível inferir que esses fatores tenham influenciado negativamente na FBN. Conforme relato do agricultor, "por muito tempo a área foi ocupada por pastagens, dando lugar aos cafeeiros, os quais são mantidos sob aplicações de fertilizantes minerais".

Sob as condições experimentais submetidas, a produtividade do feijoeiro cultivado em sucessão não foi influenciada pelos pré-cultivos avaliados (Figura 1). Embora o feijão-de-porco tenha produzido quantidades maiores de matérias fresca e seca e acumulado mais $\mathrm{N}$ do que a lablabe $\mathrm{e}$ a testemunha, esses fatores não foram suficientes para elevar, de forma significativa, a produtividade do feijoeiro. $\mathrm{O} \mathrm{N}$ disponibilizado pelas leguminosas pode ter sofrido perdas naturais, por emissões gasosas e imobilização pela microbiota, ou ter sido translocado para compor as frações da matéria orgânica do solo, não sendo absorvido pelo feijoeiro durante o seu ciclo. Essa ausência de sincronismo, entre a liberação e absorção dos nutrientes devido ao longo período de manutenção da palhada no solo, influenciou na obtenção desses resultados.

Figura 1. Produtividade do feijoeiro cultivado em sucessão aos adubos verdes. Araponga, Minas Gerais

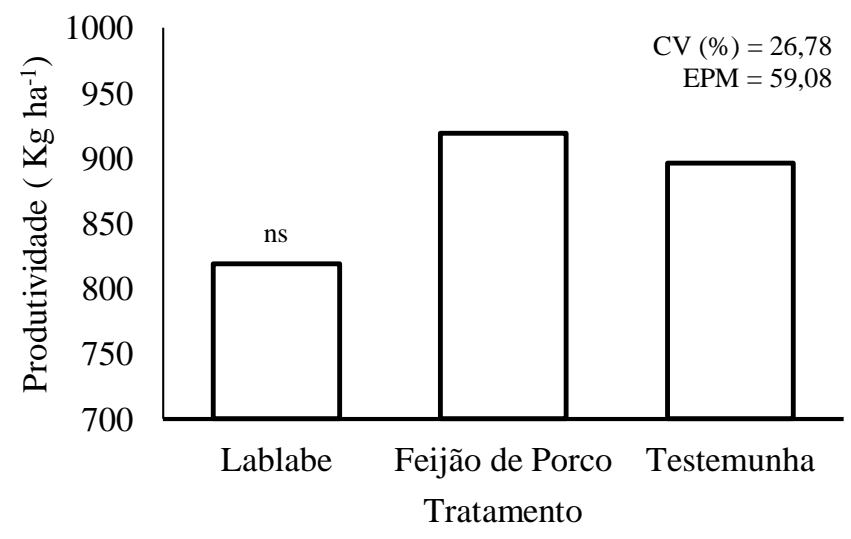

ns = Não significativo pelo teste de Tukey a 5\% de probabilidade. Dados corrigidos para a área real da parcela; CV $(\%)$ = Coeficiente de Variação; $\mathrm{EPM}=$ Erro padrão da média

Embora com pouca eficiência, o feijoeiro também é capaz de suprir parte das suas exigências de $\mathrm{N}$, por meio da FBN e, o restante da demanda, com o $\mathrm{N}$ disponível no solo (BRITO et al., 2011), sendo esse um dos motivos para recomendação de adubação nitrogenada para essa cultura, visando a atender às exigências das plantas (OLIVEIRA et 
al., 2003, FERREIRA et al., 2004). Entretanto, a elevação de $\mathrm{N}$ no solo contribuiu para menor dependência do $\mathrm{N}$ disponibilizado pelas leguminosas e pode ter reduzido a FBN do feijoeiro (BRITO et al., 2011). Na ocasião de plantio do feijoeiro, foi realizada uma adubação, que é a prática comum adotada pelo agricultor.

A participação do agricultor na condução da pesquisa foi essencial para o entendimento da influência dos fatores locais na adoção da prática estudada, favorecendo a discussão dos resultados obtidos. As suas contribuições relacionadas ao manejo do sistema produtivo, como época de corte dos adubos verdes, época dos cultivos, tipo de adubação, espaçamento e também ao histórico da área, possibilitaram correlacionar os fatores locais com os aspectos técnicocientíficos, resultando em uma visão compartilhada e de maior amplitude do processo.

Com a pesquisa participativa, evidenciou-se a importância das leguminosas na incorporação de $\mathrm{N}$ ao sistema e a preponderância das condições de manejo locais, no sucesso do processo. Neste sentido, os resultados obtidos subsidiarão o agricultor com informações importantes, a serem utilizadas nas tomadas de decisões e, neste caso específico, na escolha da espécie a ser utilizada em seu sistema de produção.

\section{CONCLUSÕES}

O feijão-de-porco acumulou mais matéria fresca, seca e $\mathrm{N}$ entre as espécies avaliadas em pré-cultivo.

$\mathrm{O}$ teor e o acúmulo de N-FBN foi maior no feijão-deporco do que na lablabe, aportando maior quantidade de $\mathrm{N}$ FBN ao sistema.

Os benefícios fornecidos pelas leguminosas não foram suficientes para elevar, de forma significativa, a produtividade do feijoeiro cultivado em sucessão.

\section{REFERÊNCIAS}

AITA, C. Dinâmica do nitrogênio no solo durante a decomposição de plantas de cobertura: efeito sobre a disponibilidade de nitrogênio para a cultura em sucessão. In: FRIES, M. R.; DALMILIN, R. S. D. (eds.). Atualização em recomendação de adubação e calagem: ênfase em plantio direto. Santa Maria: UFSM, 1997. cap. 3, p. 76- 111.

ALVARENGA, R. C.; CABEZAS, W. A. L.; CRUZ, J. C.; SANTANA, D. P. Plantas de cobertura de solo para sistema plantio direto. Informe Agropecuário, v. 22, n. 208, p. 25-36, 2001.

AMBROSANO, E. J.; CANTARELLA, H.; ROSSI, F.; SCHAMMASS, E. A.; SILVA, E. C.; AMBROSANO, G. M. B.; DIAS, F. L. F.; TRIVELIN, P. C. O.; MURAOKA, T. Desempenho de adubos verdes e da primeira soqueira de cana-de-açúcar cultivados consorciadamente. Revista Brasileira de Agroecologia, v. 8, n. 3, p. 80-90, 2013.

AMBROSANO, E. J.; FOLTRAN, D. E.; CAMARGO, M. S.; ROSSI, F.; SCHAMMASS, E. A.; SILVA, E. C.; AMBROSANO, G. M. B.; DIAS, F. L. F. Acúmulo de biomassa e nutrientes por adubos verdes e produtividade da cana-planta cultivada em sucessão, em duas localidades de
São Paulo, Brasil. Revista Brasileira de Agroecologia, v. 8, n. 1, p. 199-209, 2013.

BARRELA, T. P. Manejo de espécies de leguminosas em cafezal sob cultivo orgânico. 2010. 105f. Tese (Doutorado em Fitotecnia) - Universidade Federal de Viçosa, Viçosa. 2010.

BODDEY, R. M.; ALVES, B. J. R.; URQUIAGA, S. Quantificação da fixação biológica de nitrogênio associada a plantas utilizando o isótopo 15N. In: HUNGRIA, M. E.; ARAÙJO, R. S. (eds.). Manual de métodos empregados em estudos de microbiologia agrícola. Brasília: EMBRAP/CNPAF, 1994. cap.3, p.471-494.

BREMNER, J. M.; MULVANEY, C. S. Nitrogen total. In: PAGE, A. L. (eds.). Methods of soil analysis. $2^{\circ}$ ed. Madinson: Soil Science Society of America, 1982. cap.2. p. 595-624.

BRITO, M. M. P.; MURAOKA, T.; SILVA, E. C. Contribuição da fixação biológica de nitrogênio, fertilizante nitrogenado e nitrogênio do solo no desenvolvimento de feijão e caupi. Bragantia, v. 70, n. 1, p. 206-215, 2011.

CARDOSO, R. G. D. Período de consorciação de lablabe e feijão-de-porco com cafeeiros e trapoeraba. 2013. 109f. Tese (Doutorado em Fitotecnia) - Universidade Federal de Viçosa, Viçosa. 2013.

CARVALHO, W. P.; CARVALHO, G. J.; ABBADE NETO, D. O.; TEIXEIRA, L. G. V. Desempenho agronômico de plantas de cobertura usadas na proteção do solo no período de pousio. Pesquisa Agropecuária Brasileira, v. 48, n. 2, p. 157166, 2013.

CASTRO, C. M.; ALVES. B. J. R.; ALMEIDA, D. L.; RIBEIRO, R. L. D. Adubação verde como fonte de nitrogênio para a cultura da berinjela em sistema orgânico. Pesquisa Agropecuária Brasileira, v. 39, n. 8, p. 779-785, 2004.

CAVALCANTE, V. S.; SANTOS, V. R.; SANTOS NETO, A. L.; SANTOS, M. A. L.; SANTOS, C. G.; COSTA, L. C. Biomassa e extração de nutrientes por plantas de cobertura. Revista Brasileira de Engenharia Agrícola e Ambiental, v. 16, n. 5, p. 521-528, 2012.

CORREIA, N. M.; DURIGAN, J. C. Culturas de cobertura e sua influência na fertilidade do Solo sob sistema de plantio direto (SPD). Bioscience Journal, v. 24, n. 4, p. 20-31, 2008.

CUNHA, E. Q.; STONE, L. F.; DIDONET, A. D.; FERREIRA, E. P. B; MOREIRA, J. A. A.; LEANDRO, W. M. Atributos químicos de solo sob produção orgânica influenciados pelo preparo e por plantas de cobertura. Revista Brasileira de Engenharia Agrícola e Ambiental, v. 15, n. 10, p. 1021-1029, 2011.

DIDONET, A. D.; MOREIRA, J. A. A.; FERREIRA, E. P. B. Sistema de produção orgânico de feijão para agricultores familiares. Santo Antonio de Goiás: Embrapa Arroz e Feijão, 2009. 7p. (Embrapa Arroz e Feijão. Comunicado Técnico, 173). 
FAVERO, C.; JUCKSCH, I.; ALVARENGA, R. C.; COSTA,

L. M. Modificações na população de plantas espontâneas na presença de adubos verdes. Pesquisa Agropecuária Brasileira, v. 36, n. 11, p. 1355-1362, 2001.

FERREIRA, A. C. B.; ANDRADE, M. J. B.; ARAÚJO, G. A. Nutrição e adubação do feijoeiro. Informe Agropecuário, v. 25, n. 223, p. 61-72, 2004.

FERREIRA, D. F. Sisvar: a computer statistical analysis system. Ciência e Agrotecnologia, v. 35, n. 6, p. 1035-1042, 2011.

FERREIRA, E. P. B; STONE, L. F.; PARTELLI, F. L.; DIDONET, A. D. Produtividade do feijoeiro comum influenciada por plantas de cobertura e sistemas de manejo do solo. Revista Brasileira de Engenharia Agrícola e Ambiental, v. 15, n. 7 , p. $695-701,2011$.

GALLO, A. S.; GUIMARÃES, N, F. G.; SOUZA, M. D. B.; AGOSTINHO, P. R.; GOMES, S. S.; SILVA, R. F. Produtividade da cultura do feijoeiro em sucessão a adubos verdes, com adição de dejeto líquido de suínos. Revista de la Facultad de Agronomía, La Plata, v. 114, n. 1, p. 45-51, 2015.

LÁZARO, R. L.; COSTA, A. C. T.; SILVA, K. F.; SARTO, M. V. M.; DUARTE JÚNIOR, J. B. Produtividade de milho cultivado em sucessão à adubação verde. Pesquisa Agropecuária Tropical, v. 43, n. 1, p. 10-17, 2013.

MOITINHO, M. R.; PADOVAN, M. P.; CARNEIRO, L. F.; MOTTA, I. S.; SOUZA, E. I. S. Desempenho de adubos verdes e o efeito no feijão-comum cultivado em sucessão num agroecossistema sob bases ecológicas. In; Congresso Brasileiro de Ciência do Solo, 33, 2011, Uberlandia. Anais.. Uberlandia: SBCS, 2011. P. 140.

OKELEYE, K. A.; OKELANA, M. A. Effect of phosphorus fertilizer on nodulation, growth and yield of cowpea (Vigna unguiculata) varieties. Indian journal of agricultural Sciences, v. 67, p. 10-12, 1997.

OLIVEIRA, T. C. T.; SILVA, J. R.; FREITAS, M. S. C.; ARAÚJO, C. A. S.; LIMA, L. O. Produção de biomassa fresca e seca por diferentes leguminosas no Submédio São Francisco. Cadernos de Agroecologia, v. 8, n. 2, 2013.

OTHMAN, W. M. W.; LIE, T. A.; MANNETJE, L.; WASSINK, G. Y.; WAN-OTHMAN, W. M. Low level phosphorus supply affecting nodulation, N2 fixation and growth cowpea (Vigna unguiculata). Plant and Soil, v. 15, p. 67-74, 1991
PADOVAN, M. P.; MOITINHO, M. R.; CARNEIRO, L. F.; MOTTA, I. S.; OLIVEIRA, F. L.; SALOMÃO, G. B. Performance do feijoeiro cultivado em sucessão a adubos verdes num agroecossistema sob manejo ecológico em Dourados, Mato Grosso do Sul. Cadernos de Agroecologia, v. 7, n. 2, p 1-6, 2012.

PARTELLI, F. L.; VIEIRA, H. D.; FERREIRA, E. P. B.; VIANA, A. P.; ESPINDOLA, J. A. A.; URQUIAGA, S.; BODDEY, R. M. Biologic dinitrogen fixation and nutrient cycling in cover crops and their effect on organic Conilon coffee. Semina: Ciências Agrárias, v. 32, n. 3, p. 995-1006, 2011.

PIETSCH, G.; FRIEDEL, J. K.; FREYER, B. Lucerne management in an organic farming system under dry site conditions. Field Crops Research, v. 102, p. 104-118, 2007.

SILVA, A. M. S.; CONCEIÇÃO, V.; BORSATO, A. V.; SANTOS, A.; MOL, D. J. S.; FEIDEN, A. Avaliação participativa de adubos verdes de verão em cultivo solteiro e consorciado com milho em Mundo Novo, MS. Cadernos de Agroecologia, v. 9, n. 4, p. 1-9, 2014

SILVA, S. S.; ARAÚJO NETO, S. E. Pesquisa-ação na conversão de pastagem em roçado na agricultura familiar amazônica. Cadernos de Ciência \& Tecnologia, v. 28, n. 2, p. 509-529, 2011

SOUSA, F. F.; CARMOS, D. L.; CARNEIRO, J. E. S.; Urquiaga, S.; SANTOS, R. H. S. Legumes as green manure for common bean cultivated in two growing seasons at southeast Brazil. African Journal of Agricultural Research, v. 11, n. 49, p. 4953-4958, 2016.

VARGAS, T. O.; DINIZ, E. R.; SANTOS, R. H. S.; LIMA, C. T. A.; URQUIAGA, S.; CECON, P. R. Influência da biomassa de leguminosas sobre a produção de repolho em dois cultivos consecutivos. Horticultura Brasileira, v. 29, n. 4, p. 562-568, 2011.

VIEIRA, C. Cultivos consorciados. In: VIEIRA, C.; PAULA JR, T. J.; BORÉM, A. (eds.). Feijão. $2^{\circ}$ ed. Viçosa: UFV, 2006. cap.2, p. 493-528.

VIOLA, R.; BENIN, G.; CASSOL, L. C.; PINNOW, C.; FLORES, M. F.; BORNHOFEN, E. Adubação verde e nitrogenada na cultura do trigo em plantio direto. Bragantia, v. 72 , n. 1, p. 90-100, 2013. 